\title{
Chronic Fatigue Syndrome
}

\author{
*B. SUE GRAVES ${ }^{1}$, SIGOURNEY KAME ${ }^{1}$ \\ ${ }^{1}$ Department of Exercise Science and Health Promotion, College of Science, Florida Atlantic University \\ 777 Glades Road, Field House 11, Boca Raton, Florida 33431, USA \\ *sgraves@fau.edu
}

\begin{abstract}
Chronic fatigue syndrome is an enduring disease, characterized by a level of persistent fatigue for 6 months or a longer time period. At this time, the etiology is unknown. The other symptoms individuals effected by chronic fatigue syndrome, may experience are sore throat, headaches, impaired cognition, depression, sleep disturbances, and many others. While the diagnosis of chronic fatigue syndrome can be challenging, the Center for Disease Control (CDC) has a set of guidelines to help characterize the presence of this condition in patients. Chronic fatigue syndrome has far-reaching consequences impacting an individual's physical and mental wellbeing. The best approach in helping these individuals to still engage in physical activity is through gentle, lowlevel exercise program with the use of patient feedback to individualize the treatment as well as providing guidance and support through support groups and therapy as prescribed by a medical professional.
\end{abstract}

Key-Words: - Chronic fatigue syndrome, treatment, diagnosis, myalgic encephalomyelitis, post-viral fatigue syndrome, chronic fatigue immune dysfunction syndrome

Received: September 26, 2020. Revised: January 7, 2021. Accepted: February 4, 2021. Published: February 28, 2021.

\section{Introduction}

Many chronic diseases and conditions have evolved in the past couple of years, which have many uncertainties on specific etiology. Chronic Fatigue Syndrome (CFS) is one of these conditions. CFS is a debilitating medical condition where impacted individuals experience persistent fatigue, alongside other specific conditions that last for at least six months. Other names, currently known to describe CFS, include encephalomyelitis (ME), post-viral fatigue syndrome (PVFS), and chronic fatigue immune dysfunction syndrome (CFIDS) (3). Because these conditions are syndromes and not a pathophysiological diagnosis, it is unclear if these are all the same or of different entities (3).

CFS has an estimated prevalence of $0.2-$ $3.48 \%$ worldwide and is more common in women between the ages of 30-39 years (15). The diagnosis of CFS generates some difficulty as no specific laboratory test or biomarker exists to confirm the presence of the condition. Unfortunately, approximately $80 \%$ of cases are undiagnosed (10). Researchers and physicians are still conducting research for more details about how to differentiate chronic fatigue syndrome from any other chronic conditions (18).

Symptoms of Chronic Fatigue Syndrome (CFS)

The primary symptom of CFS is chronic incapacitating fatigue as implied in the name itself, but 20 different definitions are commonly used (15).
Several other defining symptoms exist, the most strict of which includes pain, sleep disturbance, neurocognitive disability such autonomic dysfunction while others include cold-like symptoms such as recurrent sore throat and tender lymph nodes $(14,15)$. However, the cold-like symptoms associated with CFS last months to years opposed to those associated with a viral infection often lasting days to weeks (8). Due to the lack of concise uniform definition with clear-cut criteria, lack of replicated data exists necessary for this field of research to progress (14). As there is significant overlap with other diseases, removing important biases necessary to improve the value of clinical trials remains a difficult task (15). Some individuals experience far worse symptoms than others, which is one of the difficulties CFS creates for medical doctors or other physicians to make a proper diagnosis (18). Nevertheless, many research experts are working hard to make the symptoms of this condition clear and are attempting to specifically identify the outliers (18).

Ruling out all other similar diseases that could be the cause of the symptoms felt by the affected individuals is very important, since no specific and consistent nature exists for differentiating CFS symptoms.

\section{How do affected individuals get diagnosed?}

The Center for Disease Control and Prevention (CDC) has guidelines for health professionals to make a proper diagnosis for individuals who are 
suspected to have CFS. These guidelines were developed with the Institute of Medicine (IOM) (https://www.cdc.gov/me-cfs/healthcare-

providers/diagnosis/iom-2015-diagnostic-

criteria.html ). The diagnostic criteria apply to both children and adults and require three specific symptoms plus to additional supplementary manifestations (6). The three required symptoms are:

1. A reduced ability to engage in pre-illness levels of activity in social, occupational, educational, or personal life.

2. Malaise that worsens after physical, mental, or emotional exertion

3. Non-restful sleep

Plus, at least one of the two following supplementary manifestations:

1. Cognitive impairment manifesting as problems with memory, thinking, executive functioning, and/or attention deficit.

2. Orthostatic intolerance manifesting as lightheadedness and fainting measured by orthostatic testing and evaluation

Communication with the patient is key in treating this condition. Patient understanding that CFS is an incompletely understood condition with no single clear etiology can be helpful in acceptance of the diagnosis (2).

\section{How does CFS affect the individuals?}

Individuals, who are impacted by CFS, experience the severe and disabling effects that go along with the fatigue and issues with their mental and physical functionality. CFS affects all genders, racial, ethnic, and socioeconomic populations and can begin as early as five years of age (7). CFS is often associated with depression, which has led many physicians to believe that CFS is a purely somatic illness (23). Even though no specific cure exists for CFS, many treatments and therapies exist that may help to lessen the pain and suffering of the individuals affected by this chronic condition.

For some time now, the officially recommended treatments for chronic fatigue syndrome (CFS) in many countries have been graded exercise therapy (GET) and cognitive behavioral therapy (CBT) (21). CBT, especially, is a well-known therapy used among this population that can be very effective. Treatment followed cognitive behavioral principles derived from work on the management of chronic pain but adapted for the particular problems of CFS (5). Cognitive behavioral therapy can be done, both individually and in groups (22). In adolescents, internet-based consultations may be effective (22). Individually adjusted increases in activity are an integral part of cognitive behavioral therapy but may also be beneficial alone (22). No sign of any increase in serious adverse events following these types of treatments has been observed (22). Balance Error Scoring System (BESS).

\section{Can you still exercise while diagnosed with this condition?}

Profound fatigue, made worse by minimal physical or mental exertion, lies at the core of CFS, but no other cardinal features exists, abnormal physical signs or laboratory tests, which can confirm the 'diagnosis ' (20), as stated previously. Since vigorous exercise can worsen the symptoms of these individuals, caution must be employed when increasing. Many individuals with CFS also complain of muscle pain (myalgia) and joint pain (arthralgia) without swelling and redness on a regular basis, which should be taken in consideration when deciding to add physical activity and exercise.

A study investigating muscular function in patients with CFS reported reduced work capacity compared with healthy control subjects (7). No consistent evidence of a primary disorder of muscle exists in most studies, and no evidence of any changes in muscle structure that could not be explained by the consequence of illness (20). This information is consistent with the frequent observation that fatigue in CFS affects both physical and mental functioning, which is worsened by both physical and mental effort (20). Research has been conducted to investigate the strength of the muscles in these individuals might be affected by the syndrome in specific ways, but no significant correlations had been found with this chronic condition. As muscular symptoms are a substantial part of the syndrome, researchers have looked for pathophysiological explanations, but no underlying pathology in muscle tissue has been identified (11). CFS patients show normal muscle physiology before and after exercise (11).

\section{What are the restrictions these individuals have?}

As many other chronic conditions, CFS has some restrictions when attempting to live a normal lifestyle. These individuals are usually still able to continue working at their job and be full-time in school, whereas some do have to stop working, especially if their job consists of heavy-duty work. Reports exist that patients with CFS show decreased cognitive performance after maximal physical activity compared with healthy control subjects (7). Some jobs do not necessarily require the individuals to fully quit, if their symptoms are not that severe, since they might be able to change from full-time to 
part-time. If the symptoms are very severe and unbearable, these specific individuals may also be able to work from home if the job allows this alternative, especially when they know the reason behind this decision (13).

Table 1: Example of a Safe Exercise Program

\begin{tabular}{|c|c|c|c|}
\hline Mode & Frequency & $\frac{\text { Duratio }}{\mathrm{n}}$ & Intensity \\
\hline Aerobic & $\begin{array}{l}4-5 \text { days/wee } \\
\text { ks }\end{array}$ & $\begin{array}{l}\text { Begin at } \\
\text { any } \\
\text { duration } \\
\text { they can } \\
\text { do. } \\
\text {-Goal: } \\
40 \\
\text { minutes } \\
\text { per } \\
\text { session } \\
-10 \text { to } 20 \\
\text { minutes } \\
\text { if the } \\
\text { session } \\
\text { is } \\
\text { combine } \\
d \text { with } \\
\text { strength } \\
\text { workout } \\
\text { s }\end{array}$ & $\begin{array}{l}\text { Start at } \\
\text { their own } \\
\text { pace } \\
\text { Example: } \\
\text { Casual } \\
\text { walk in } \\
\text { safe } \\
\text { environme } \\
\text { nt } \\
\text { Gradually } \\
\text { increase to } \\
\text { an RPE of } \\
3 \text { to } 5 \text { out } \\
\text { of } 10\end{array}$ \\
\hline Strength & $\begin{array}{l}2-3 \\
\text { Days/weeks }\end{array}$ & $\begin{array}{l}\text { Body- } \\
\text { Weight } \\
\text { exercise } \\
\text { s: } \\
1 \text { set of } \\
\text { function } \\
\text { al } \\
\text { exercise } \\
\mathrm{s}(8-12 \\
\text { reps }) \\
\text { Weights } \\
: 1 \text { set of } \\
8 \text {-12 } \\
\text { reps to } \\
\text { fatigue }\end{array}$ & $\begin{array}{l}\text {-Sit to } \\
\text { stand: } 8 \\
\text { reps } \\
- \\
\text { Alternativ } \\
\text { e: Stair } \\
\text { steps } \\
\text { (standard } \\
\text { is } 10 \text { steps) } \\
\text { or walking } \\
\text { in place } \\
\text { for one } \\
\text { minute. } \\
\text { Arm curls: } \\
8 \text { reps with } \\
2 \text { to } 4 \text { kg (4 } \\
\text { to } 8 \\
\text { pounds) }\end{array}$ \\
\hline$\frac{\text { Flexibili }}{\underline{\text { ty }}}$ & 3 days/weeks & $\begin{array}{l}\text { Hold } \\
\text { stretch } \\
\text { for } 5 \\
\text { seconds } \\
\text { then } \\
\text { slowly } \\
\text { increase }\end{array}$ & $\begin{array}{l}\text { Maintain } \\
\text { stretch } \\
\text { below } \\
\text { discomfort } \\
\text { point }\end{array}$ \\
\hline
\end{tabular}

\begin{tabular}{|c|c|c|c|}
\hline & & $\begin{array}{l}\text { to } 20 \\
\text { seconds }\end{array}$ & \\
\hline $\begin{array}{l}\text { Warm- } \\
\frac{\text { Up/ }}{\text { Cool- }} \\
\frac{\text { Down }}{}\end{array}$ & $\begin{array}{lr}\text { Before } & \text { and } \\
\text { after } & \text { each } \\
\text { session } & \end{array}$ & $\begin{array}{l}10-15 \\
\text { minutes }\end{array}$ & $\begin{array}{l}\text { Easy } \\
\text { RPE }<3 \text { to } \\
5 \text { out of } 10\end{array}$ \\
\hline $\begin{array}{l}\text { RPE }= \\
\text { Rating o } \\
\text { perceive } \\
\mathrm{d} \\
\text { exertion } \\
(0-10)\end{array}$ & & & \\
\hline
\end{tabular}

CFS is very often also considered to be fibromyalgia by some, whereas, others argue that these are two totally different conditions. Nevertheless, many studies looked at the fact if muscle relaxation can help lessen some of the symptoms in both CFS and fibromyalgia, whether they are considered the same or not. Very limited evidence exists for the isolated pain-relieving effects of muscle relaxation in fibromyalgia, possibly other modalities (massage, exercise, biofeedback) are more beneficial or need to be added to generate a synergistic effect (12).

How can you prescribe a safe exercise program for these individuals?

Exercise and regular physical activity are widely known to result healthy benefits, which can improve individuals in their quality of life and reduce many disabilities or conditions. In many theoretical research models on pain and fatigue, a decreased level of physical activities (physical disuse) is assumed an important factor leading to and maintain chronicity of pain and fatigue (19). These models suggest that, as a consequence of long-term physical disuse, the condition of the individual gets worse, resulting in tiredness and pain during daily activities (19). Absence or a lack of physical activity is considered a risk factor that leads to increased chronic diseases, which one is CFS. Ideally, evaluation of physical function in people with chronic pain and chronic fatigue disorders should rely on a combination of clinical assessment of impairments, behavioral observation of physical function, and patient self-report (17). Despite this issue, limited evidence exists regarding the acceptability, reliability and validity of submaximal and maximal exercise tests measuring physical fitness and capacity in this group of people (17).

When writing out an actual exercise prescription for individuals, one should focus on the following basic method (traditional) called FITT. FITT stands for Frequency, Intensity, Time and Type of exercise (9). - Frequency: How "often" a particular exercise or workout session is performed (days per week) 
- Intensity: How "hard" that particular exercise or workout session should/can be done

- Time: How "long" that particular exercise or workout session will last

- Type: A "specific" kind of exercise

Before writing out this specific individual description with chronic additions, in this case CFS, the following should be assessed and screened (9):

- Current health status

- Current level of physical activity

- Exertional symptoms that may limit physical activity

- Evaluate physical function and performance

In addition a Rate of Perceived Exertion (RPE) Scale can be used to measure the intensity of the exercise an individual may do (See Table 2). In other words, the CFS individual can use numbers in order to identify how easy or difficult the exercise or activity may be. The number would include how tired an individual's legs, arms, shortness or breath and overall feeling. The progressive scale is from 0 to 10 , with 0 meaning nothing at all, such as just sitting in a chair resting. A 3 would be a moderate activity. The 10 would be used of how that individual would feel at the end of a very stressful activity or an exercise stress test (1).

Table 2: 0-10 Points; Rate of Perceived Exertion (RPE Scale)

\begin{tabular}{|l|l|}
\hline$\underline{\text { RPE }}$ & $\begin{array}{l}\text { Subjective } \\
\text { Description }\end{array}$ \\
\hline 0 & Nothing (rest) \\
\hline 0.5 & Very, very light \\
\hline 1 & Very light \\
\hline 2 & Light \\
\hline 3 & Moderate \\
\hline 4 & Somewhat hard \\
\hline 5 & Hard \\
\hline 6 & \\
\hline 7 & Very hard \\
\hline 8 & \\
\hline 9 & \\
\hline 10 & Very, very hard \\
\hline
\end{tabular}

Some physical performance assessments that can be done with these individuals are (17):

Chair Stand Test: Assess lower body muscle endurance.

The individual starts by sitting in the middle of a chair (without wheels) with arms crossed against chest, back straight and feet flat on the floor. The individual is to rise up to a full standing position and then sit back in the chair. The goal is to curl the weight through the full range of motion as many times in 30 seconds.

Arm Curl Test: Assess upper body muscle endurance.

The individual starts by sitting in a chair (without wheels) with their dominant side of body close to the side edge of the chair, back straight and feet flat on the floor. The weight (5-lbs dumbbell for women and 8-lbs dumbbell for men) should be curled up to a flexed position and then returned to a fully extended position. The goal is to curl the weight through the full range of motion as many times in 30 seconds.

\section{Six Minute Walk Test: Assess aerobic stability.}

The individual walks as quickly as possible around a 50 -yard rectangular area ( 20 yards by 5 yards). The goal is to cover as much distance as possible in 6 minutes, which is their score at the end (total number of yards walked in 6 minutes).

\section{Chair Sit and Reach: Assess general flexibility.}

The individual starts by sitting at the edge of a chair (without wheels) with one leg bent and feet flat on the floor and the other leg extended (whichever leg they prefer). The individual will try to reach as far as possible toward or passed their toes. The score is the distance between the middle fingers and the top of the shoe.

Back Scratch Test: Assess shoulder flexibility, specifically.

While standing the individual places their preferred hand over the same shoulder with the elbow pointing up. The other hand (Palms up) tries to reach up from around the back to touch or overlap the extended middle fingers of hands over the shoulder. The score is the distance between/overlap of the middle fingers.

\section{8-Foot-up-and-Go Test: Assess agility.}

A chair (without wheels) is placed against a wall with a cone placed 8 feet in front of the chair. The individual starts by sitting in the middle of a chair with hands on the thigh, back straight and feet flat on the floor. The goal is to walk around the cone as fast as possible and then sits back in the chair. The score is the time it takes to complete the exercise.

The previous assessments can be very valuable for personal trainers or others in the fitness industry, which will help them find out where their CFS client is in regard to their capability. Checking the CFS individual's blood pressure and heart rate is also a very important factor that can help personal trainers and others in the fitness industry assess their clients/patients. The next page has included a table with a brief example of a safe/simple exercise 
program for these individuals with respect to the FITT model. Personal trainers or others in the fitness industry are should be flexible when creating these safe and effective exercise programs, considering what motivates the individuals, what their limits are and pushing them within that perimeter.

\section{Conclusion}

The body of research is growing for CFS, but substantial steps need to be taken to level the field and ensure quality studies in the future. This begins with a concise definition of the condition for use in research in order to develop reproducible data. In the meanwhile, healthcare professionals should use the most up-to-date information to provide the best multidisciplinary care possible to the affected individuals including, but not limited to, behavioral therapy, pharmacotherapies, and physical therapy. As this condition is chronic, follow up is important to ensure the patient is adhering to treatment and if treatment is failing, to adjust accordingly. Physicians may also suggest sleep aids and pain-relieving medications for specific patients using appropriate clinical judgement.

\section{Consent:}

Informed consent was obtained from the patient to publish case details, test results, and images.

Competing interests:

No competing interests to disclose.

\section{References:}

[1]. American College of Sports Medicine. (2017). Guidelines for Exercise Testing and Prescription 10th Ed. 2017. Lippincott Williams \& Wilkins

[2]. Arroll, M. and Arroll, B. Chronic fatigue syndrome-A patient centered approach to management. Australian Family Physician 42: 191-193, 2013.

[3]. Bailey, S. P. \& Nieman, D. C. (2016). Chronic Fatigue Syndrome. In G. E. Moore, J. L. Durstine \& P. L. Painter (Eds.), ACSM's Exercise Management for Persons With Chronic Diseases and Disabilities (4 ${ }^{\text {th }}$ ed., pp. 215-219). Champaign, IL: Human Kinetics.

[4]. Bjorklund G, Dadar M, Pen JJ, Chirumbolo S, Aaseth J. Chronic fatigue syndrome (CFS): Suggestions for a nutritional treatment in the therapeutic approach. Biomedicine \&
Pharmacotherapy 109: 1000-1007, 2019.

[5]. Bonner D, Ron M, Chalder T, Butler S and Wessely S. Chronic fatigue syndrome: a follow up study. Journal of Neurology, Neurosurgery, and Psychiatry 57:617-621, 1994.

[6]. CDC - ME/CFS - Information for Healthcare Providers. https://www.cdc.gov/me-cfs/healthcareproviders/diagnosis/iom-2015diagnostic-criteria.html. November 19, 2019

[7]. Craig T and Kakumanu S. Chronic Fatigue Syndrome: Evaluation and Treatment. American Family Physician 65: 1083-1090, 2002.

[8]. Dawes, J and Stephenson, MD. Training Individuals With Chronic Fatigue Syndrome. Strength and Conditioning Journal 30: 55-57, 2008.

[9]. Evengard B, Schacterle RS and Komaroff AL. Chronic fatigue syndrome: new insights and old ignorance. Journal of Internal Medicine 246: 455-469, 1999.

[10]. Griffith, J.P. and Zarrouf, F.A. (2008). A systematic review of chronic fatigue syndrome: don't assume it's depression. Primary care companion to the Journal of clinical psychiatry, 10(2), 120.

[11]. Larun L, Brurberg KG, OdgaardJensen, J, and Price JR, Exercise therapy for chronic fatigue syndrome, Cochrane Database Syst Rev 4:1-138, 2017.

[12]. Meeus M, Nijs J, Vanderheiden T, Baert I, Descheemaeker F and Filip Struyf. The effect of relaxation therapy on autonomic functioning, symptoms and daily functioning, in patients with chronic fatigue syndrome or fibromyalgia: a systematic review. Clinical Rehabilitation 29: 221-233, 2014.

[13]. Morris G, Maes M, Berk M, Puri BK. Myalgic encephalomyelitis or chronic fatigue syndrome: how could the illness develop?. Metab Brain Dis. 2019;34(2):385-415. doi:10.1007/s11011-019-0388-6

[14]. National ME/FM Action Network Myalgic

Encephalomyelitis/Chronic Fatigue Syndrome and Fibromyalgia Findings 
from the 2014 Canadian Community Health Survey (2014). https://www.mefmaction.com/docs/CC HS_Stats 2014.pdf (Accessed July 21, 2020).

[15]. Rasa S, Nora-Krukle Z, Henning N, et al. Chronic viral infections in myalgic encephalomyelitis/chronic fatigue syndrome (ME/CFS). $J$ Transl Med. 2018;16(1):268. Published 2018 Oct 1. doi:10.1186/s12967-018-1644-y

[16]. Ratter J, Radlinger L and Lucas C. Several submaximal exercise tests are reliable, valid and acceptable in people with chronic pain, fibromyalgia or chronic fatigue: a systematic review. Journal of Physiotherapy 60: 144-150, 2014.

[17]. Rikli, RE and Jones CJ. The development and validation of a functional fitness test from communityresiding older adults. $\mathrm{J}$ of Aging and Physical activity (7): 162-181, 1999a.

[18]. Sharpe, M. and Greco, M. Chronic fatigue syndrome and an illness-focused approach to care. Med Humanities 45(2):183-187, 2019.

[19]. Van Weering, M., VollenbroekHutten, M. M. R., Kotte, E. M. \& Hermens, H. J. (2017) Daily Physical Activities of Patients with Chronic Pain or Fatigue versus Asymptomatic Controls. A Systematic Review. SAGE journals, 21(11), 1007-1023.

[20]. Wessely, S. Chronic Fatigue Syndrome- Summary of a Report of A Joint Committee of the Royal Colleges of Physicians, Psychiatrists and General Practitioners. Journal of the Royal College of Physicians of London 30: 497-504, 1996.

[21]. Wilshire CE, Kindlon T, Courtney R, Matthees A, Tuller D, Geraghty K and Levin B. Rethinking the treatment of chronic fatigue syndrome - a reanalysis and evaluation of findings from a recent major trial of graded exercise and CBT. BMC Psychology 6: 1-12, 2018.

[22]. Wyller VB, Reme SR and Mollnes TE. Chronic fatigue syndrome/myalgic encephalo-myelitis - pathophysiology, diagnosis and treatment. Journal of the Norwegian Medical Association 135: 2172-2175, 2015.
[23]. Yancey JR and Thomas SM. Chronic Fatigue Syndrome: Diagnosis and Treatment. American Family Physician 86: 741-746, 2012.

\section{Creative Commons Attribution \\ License 4.0 (Attribution 4.0 \\ International, CC BY 4.0)}

This article is published under the terms of the Creative Commons Attribution License 4.0 https://creativecommons.org/licenses/by/4.0/deed.en US 